\title{
Newer aspects of micronutrients in chronic disease: vitamin $\mathbf{E}$
}

\author{
BY P. A. MORRISSEY, P. B. QUINN AND P. J. A. SHEEHY \\ Department of Nutrition, University College, Cork, Republic of Ireland
}

Vitamin $\mathrm{E}$ is an essential fat-soluble vitamin that was discovered in 1922 by Evans and Bishop. For many years after its discovery vitamin $E$ remained a mysterious vitamin, and it took over four decades before it was proved that vitamin E deficiency could cause disease in humans. In recent years, vitamin $E$ has been linked to several distinct clinical problems in humans, including haemolytic anaemia in premature newborn infants, decreased erythrocyte stability in patients with cystic fibrosis and "brown bowel syndrome'. Other studies demonstrated that vitamin $\mathrm{E}$ played an essential role in maintaining the integrity of neuromuscular systems and retina.

The most significant development in the history of vitamin $\mathrm{E}$ was the identification that the vitamin is an effective lipid-soluble scavenger of lipid peroxyl radicals and, while present in very low concentrations, it is extremely efficient in protecting against lipid peroxidation in membranes. Free-radical-mediated lipid peroxidation is implicated in several diseases including: cancer, rheumatoid arthritis, drug-associated toxicity, coronary heart disease, diabetes, and acute clinical conditions, such as ischaemia-reperfusion injury (Halliwell, 1987; Halliwell \& Gutteridge, 1990; Cheeseman \& Slater, 1993).

\section{CHEMISTRY OF VITAMIN E}

The term 'vitamin E' is used to describe all tocopherols and tocotrienols that exhibit the general physiological activity of alleviating any symptoms related to vitamin $\mathrm{E}$ deficiency. $\alpha$-Tocopherol (TOH), the main component of vitamin $E$, has an interesting structure (Fig. 1). It is a derivative of 2-methyl-6-chromanol on to which a saturated hydrophobic $\mathrm{C}_{16}$ isoprenoid tail or chain is attached at $\mathrm{C}-2$ and which is methylated at $C-5, C-7$ and $C-8$. The other forms $(\beta-, \gamma-, \delta-)$ differ in the number and position of the methyl groups on the chromanol ring. Tocotrienols differ from tocopherols in that the side chain is unsaturated at C-3', C-7' and C-11'. TOH is an indispensible component of biological membranes with membrane-stabilizing properties (Diplock, 1985). The hydrophobic tail is the means by which $\mathrm{TOH}$ inserts into lipoproteins or anchors into membranes next to unsaturated fatty acids, where it is stabilized by London-van der Waal's dispersion-attraction forces (Diplock, 1985). The isoprenoid chain is considered important for proper orientation of the molecule in the membrane and is not involved in its antioxidant properties. The chromanol nucleus lies at the surface of a lipoprotein or at the surface of membranes, and it is the phenolic hydroxyl group which quenches free radicals (Packer, 1993b).

\section{LIPID PEROXIDATION}

Before discussing the functions of vitamin $\mathrm{E}(\mathrm{TOH})$ in biological systems, we intend briefly to review the mechanism of lipid oxidation. Lipid oxidation is a free-radicalmediated chain reaction which is initiated by the abstraction of a labile hydrogen from a 


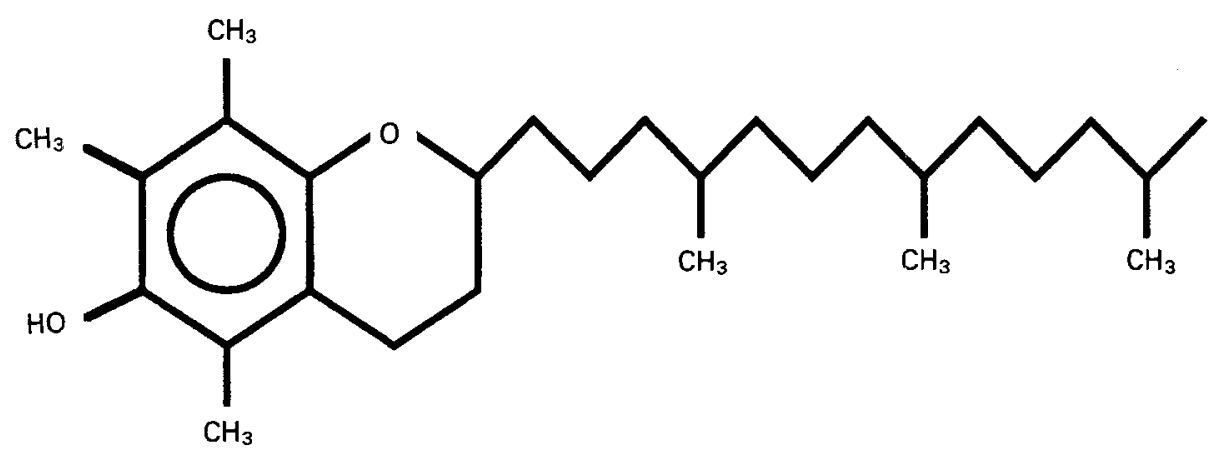

Fig. 1. Structure of $\alpha$-tocopherol.

methylene group adjacent to a double bond of a polyunsaturated fatty acid ( $\mathrm{RH}$ ) by the action of the highly active hydroxyl radical $\left(\mathrm{OH}^{\bullet}\right)$, or certain $\mathrm{Fe}-\mathrm{O}$ complexes such as ferryl or perferryl radicals (Halliwell \& Chirico, 1993). Buettner (1993) reviewed the thermodynamics of free-radical reactions. Using standard one-electron reduction potentials $\left(\mathrm{E}^{0}\right)$, he predicted a 'hierarchy, or pecking order' for the course of free-radical processes. Each oxidized species (higher $\mathrm{E}^{0}$ ) is capable of abstracting an electron (or hydrogen atom) from any reduced species (lower $\mathrm{E}^{0}$ ) listed below it. Thus, the hydroxyl radical $(\mathrm{OH} \bullet)$, which is at the top of the pecking order and considered to be the most potent oxidant encountered in biological systems, can oxidize all the reduced species below it (Table 1 of Buettner, 1993). The driving force for the reaction is the difference in potential $\left(\Delta \mathrm{E}^{0}\right)$ between the two reaction systems.

For example, the $\mathrm{OH}^{\bullet}, \mathrm{H}^{+} / \mathrm{H}_{2} \mathrm{O}$ couple has $\mathrm{E}^{0}=+2310 \mathrm{mV}$ and the $\mathrm{R}^{\cdot}, \mathrm{H}^{+} / \mathrm{RH}$ couple has $\mathrm{E}^{0}=+600 \mathrm{mV} ; \Delta \mathrm{E}^{0}=+1700$. Thus, $\mathrm{OH} \cdot$ can in principle be remarkably effective in bringing about initiation of lipid peroxidation:

$$
\mathrm{RH}+\mathrm{OH} \cdot \stackrel{\Delta \mathrm{E}^{0}=+1700 \mathrm{mV}}{\longrightarrow} \mathrm{R} \cdot+\mathrm{H}_{2} \mathrm{O} .
$$

The fatty acid radical $(R \cdot)$ reacts rapidly with $\mathrm{O}_{2}$ to form a fatty acid peroxyl radical (ROO•):

$$
\mathrm{R} \cdot+\mathrm{O}_{2} \underset{k_{1} 3 \times 10^{8 / \mathrm{M} . \mathrm{s}}}{\longrightarrow} \mathrm{ROO} \cdot
$$

where $k_{1}$ is rate-constant. Because ROO• is more highly oxidized (higher in the pecking order) than the fatty acyl radical or RH, it will preferentially oxidize further unsaturated fatty acids and propagate the chain reaction:

$$
\mathrm{ROO} \cdot+\mathrm{RH} \frac{\Delta \mathrm{E}^{0}=+400 \mathrm{mV}}{k_{2}} \mathrm{ROOH}+\mathrm{R} \cdot
$$

(reaction 2)

The rate-constant $k_{2}$ for the propagation step is relatively low, 10/M.s (Buettner, 1993) or $10^{2} / \mathrm{M} \cdot \mathrm{s}$ (Niki \& Matsuo, 1993).

Lipid hydroperoxides formed in the propagation reaction are both products of the peroxidative process and substrates for further reaction with $\mathrm{Fe}$ and $\mathrm{Cu}$ to yield ROOand the alkoxyl radical ( $\mathrm{RO} \bullet$ ). Reducing agents (e.g. ascorbates, superoxide) convert $\mathrm{Fe}^{3+}$ and $\mathrm{Cu}^{2+}$ to the more reactive $\mathrm{Fe}^{2+}$ and $\mathrm{Cu}^{+}$(Kappus, 1991). The toxicity of 
strong reductants, such as the paraquat radical, is associated with the reduction of $\mathrm{O}_{2}$ to $\mathrm{O}_{2}{ }^{--}$and $\mathrm{Fe}^{3+}$ to $\mathrm{Fe}^{2+}$, thereby producing the reduced metal required for the Fenton reaction (Kalyanaraman et al. 1991):

$$
\mathrm{O}_{2^{--}}+\mathrm{Fe}^{3+} \longrightarrow \mathrm{Fe}^{2+}+\mathrm{O}_{2} .
$$

The $\mathrm{Fe}^{2+}$ may react with $\mathrm{H}_{2} \mathrm{O}_{2}$ in the Fenton reaction and generate the powerful $\mathrm{OH} \cdot$ free radical:

$$
\mathrm{Fe}^{2+}+\mathrm{H}_{2} \mathrm{O}_{2} \longrightarrow \mathrm{Fe}^{3+}+\mathrm{OH}^{\bullet}+\mathrm{OH}^{-} .
$$

Alternatively, the $\mathrm{Fe}^{2+}$ reductively cleaves $\mathrm{ROOH}$ (reaction 2) to yield the lipid RO:

$$
\mathrm{Fe}^{2+}+\mathrm{ROOH} \longrightarrow \mathrm{Fe}^{3+}+\mathrm{RO} \cdot+\mathrm{OH}^{-} .
$$

According to Beuttner (1993) the RO• is higher on the pecking order than RH and $\mathrm{ROOH}$, and, thus, can initiate additional reactions:

$$
\mathrm{RO} \cdot+\mathrm{RH} \stackrel{\Delta \mathrm{E}^{0}=+1000 \mathrm{mV}}{\longrightarrow} \mathrm{ROH}+\mathrm{R} \cdot
$$

The RO• can undergo $\beta$-scission and degrade to alkyl radicals $\left(\mathrm{R}^{\prime} \mathrm{CH}_{2}{ }^{\bullet}\right)$ and a range of aldehydes $\left(\mathrm{R}^{\prime \prime} \mathrm{CHO}\right)$ depending on the particular hydroperoxide which is present:

$$
\mathrm{RO} \cdot \longrightarrow \mathrm{R}^{\prime} \mathrm{CH}_{2}{ }^{\bullet}+\mathrm{R}^{\prime \prime} \mathrm{CHO} \text {. }
$$

$\mathrm{R}^{\prime} \mathrm{CH}_{2}{ }^{\bullet}$ are also higher on the pecking order than $\mathrm{RH}$ or $\mathrm{ROOH}$, and further chain reactions can be initiated, resulting in the formation of ethene and pentane. The aldehydes formed, including hexanal, malondialdehyde and 4-hydroxynonenal, can react readily with $\epsilon$-amino groups of proteins to yield Maillard-type complexes.

\section{ANTIOXIDANT ACTIVITY OF VITAMIN E}

The antioxidant activities of chain-breaking antioxidants are determined primarily by how rapidly they scavenge peroxyl radicals. When the chromanol phenolic group of TOH encounters an ROO it forms a hydroperoxide, and in the process a tocopheroxyl radical (TO•) is formed:

$$
\mathrm{TOH}+\mathrm{ROO} \cdot \frac{\Delta \mathrm{E}^{0}=+500 \mathrm{mV}}{k_{3}} \mathrm{ROOH}+\mathrm{TO} \cdot
$$

(reaction 3)

The rate-constant $\left(k_{3}\right)$ for this chain-inhibition reaction is given as $8 \times 10^{4} / \mathrm{M}$.s (Buettner, 1993) or $10 \%$ M.s (Niki \& Matsuo, 1993). Since the rate-constant $\left(k_{2}\right)$ for the chain propagation (reaction 2; approximately $10^{2} / \mathrm{M} . \mathrm{s}$ ) is much lower than that for chain initiation $\left(k_{3}\right)$, TOH may outcompete the propagation reaction and scavenge the ROOabout $10^{4}$ times faster than polyunsaturated lipids react with the ROO- Thus, the kinetic properties of antioxidants, and in particular $\mathrm{TOH}$, require that only relatively small amounts be present for them to act as effective antioxidants.

The concentration of TOH in biological membranes is approximately 1 mol per 1000 mol RH (i.e. 1:103; Burton et al. 1983). We can then calculate the effective antioxidant capacity of $\mathrm{TOH}$ in biological systems as follows:

$$
\frac{\text { Rate of reaction } 3}{\text { Rate of reaction } 2}=\frac{k_{3}[\mathrm{ROO} \cdot][\mathrm{TOH}]}{k_{2}[\mathrm{ROO} \cdot][\mathrm{RH}]}=\frac{10^{6}}{10^{2}} \times \frac{1}{10^{3}}=10 .
$$


This gives an effective value of the rate of chain inhibition: that of chain propagation of $10: 1$, so that about $90 \%$ of the ROO- are scavenged by TOH before they can attack another RH (Buettner, 1993; Niki \& Matsuo, 1993). A 50\% reduction in the TOH concentration in the membrane (to $0.5 \mathrm{~mol}$ per $1000 \mathrm{~mol} \mathrm{RH}$ ) would only reduce this value to about $83 \%$, showing that the system can effectively scavenge ROO- even in the event of substantial TOH depletion.

These calculations do not take account of the effect of fatty acid composition on oxidation rate. Increasing the degree of unsaturation of lipids in membranes or lipoproteins by dietary means increases the concentration of labile bis-allylic hydrogen atoms, making it more likely that one of these hydrogen atoms may be abstracted by ROO or other radicals. The relative oxidative rates of fatty acids containing $1,2,3,4,5$ and 6 double-bonds are 0.025, 1, 2, 4, 6 and 8 respectively (Horwitt, 1986), and it may be argued that these values should be incorporated into the calculation of effective antioxidant capacity. Packer (1993a) suggested that vitamin E requirements may vary up to five-fold depending on tissue fatty acid composition due to previous dietary intake.

\section{FUNCTION OF VITAMIN E IN MEMBRANES}

According to Diplock (1985) the specific location of TOH in the membrane allows it to function very efficiently compared with other antioxidants. The molecule is anchored in the highly hydrophobic hydrocarbon part of the membrane bilayer by the phytyl chain, which is $\mathrm{C}_{13}$. This is just the right length to position the chromanol nucleus at the membrane interface (Kagan \& Quinn, 1988). In this position the chromanol ring has considerable mobility; it is able to quench free radicals and can harvest or collect the antioxidant capacity of other lipid-soluble antioxidants (e.g. ubiquinols) and watersoluble reductants such as ascorbate and glutathione (Packer \& Kagan, 1993).

The problem with the proposed model is that the phenolic $\mathrm{OH}$ group of $\mathrm{TOH}$ is at the membrane-water interface and the phytyl chain lies parallel to the highly susceptible fatty acyl chain in the membrane, where the free radical ( $\mathrm{R}^{\cdot}$ ) is formed. As already outlined, this acyl radical reacts very rapidly to produce an ROO•. The physical separation of the radical site on the fatty acyl chain and the antioxidant phenolic group on the chromanol ring would appear to preclude any significant reaction between ROOand $\mathrm{TOH}$. However, the formation of the lipid ROO- alters the hydrophobicity of the fatty acyl chain (Barclay \& Ingold, 1981; Essenden et al. 1984). The polarity of the $\mathrm{ROO} \cdot$ is increased and it diffuses out of the autoxidizable, non-polar, interior region of the bilayer and into the non-autoxidizable polar membrane-water interface. The proximity at the interface of the anchored phenol on the chromanol ring allows for rapid repair of the $\mathrm{ROO} \cdot$ group. As a consequence, chain propagation will be retarded and chain termination accelerated. Since the phytyl chain of TOH is relatively inert, its hydrophobicity is unlikely to be modified, and this constant environment may promote the 'floating' of the newly formed hydrophilic ROO- to the membrane-water interface.

\section{REGENERATION OF $\alpha$-TOCOPHEROL}

The overall antioxidant activity of $\mathrm{TOH}$ depends also on the fate of the TO formed when it scavenges lipid ROO•. It may scavenge another lipid ROO• to form a non-radical adduct (Burton \& Traber, 1990; Kaur \& Perkins, 1991), react with another 
TO to form a dimer, or it can be readily regenerated, thereby recycling TOH (Kagan et al. 1992; Packer, 1993b; Packer \& Kagan, 1993). Further, it was suggested that the remarkable antioxidant properties of vitamin $\mathrm{E}$ may be explained by its ability to be efficiently re-reduced from its radical form to its native state by other intracellular reductants. Packer's group (Kagan et al. 1990a,b, 1992) used a number of methods to generate chromanoxyl radicals from vitamin $\mathrm{E}$ and showed that ascorbate is efficient in regenerating endogenous vitamin $\mathrm{E}$ and exogenously added chromanols, not only in liposomes, but also in human low-density lipoprotein (LDL), liver microsomes and submitochondrial particles. In addition, NADPH or NADH in microsomes, as well as $\mathrm{NADH}$ or succinate in mitochondria, reduce the chromanoxyl radical and prevent the accumulation of the radical until the substrates are fully consumed. Ubiquinones synergistically enhance the enzymic NADH- and NADPH-dependent recycling of chromanoxyl radicals by electron transport. Reduced glutathione increases the efficiency of NADPH in the recycling effect, but is without effect in the absence of NADPH. Reduced thiols (glutathione and dihydrolipoate) synergistically enhance the ascorbatedependent recycling of $\mathrm{TOH}$ by regenerating ascorbate from dehydroascorbate. Packer \& Kagan (1993) concluded that the unique ability of low concentrations of vitamin $\mathrm{E}$ to act as a highly efficient antioxidant in biological systems is due to its capacity to act as a membrane free-radical harvesting centre. Thus, its antioxidant power is derived from other intracellular reductants.

\section{VITAMIN E AND DISEASE}

The preceding discussion implicated vitamin $\mathrm{E}$ as the major, if not the only, chainbreaking antioxidant in membranes. Its remarkable antioxidant properties can best be explained by its ability to be re-reduced from its radical form by a range of reductants which act independently or synergistically. Under conditions in which vitamin $\mathrm{E}$ 'harvests' the antioxidant power of water-and lipid-soluble substances, then the loss or consumption of vitamin $E$ is prevented. In many instances of exposure to oxidative stress, the armoury of defensive systems (preventative and chain-breaking antioxidants) are unable to cope with the oxidative stress overload. The normal defensive mechanisms may also be weakened by nutritional deficiencies of essential minerals such as $\mathrm{Zn}, \mathrm{Cu}$, $\mathrm{Mn}$ and Se, which are incorporated into protective antioxidant enzymes, low vitamin A status, or genetic deficiencies (e.g. cystic fibrosis). Under these conditions, the recycling mechanisms which protect vitamin $\mathrm{E}$ are lost, and molecular damage to lipids, proteins and membranes becomes apparent.

\section{VITAMIN E AND CANCER}

Excess free radicals are believed to be involved in the initiation and growth of many cancers. Vitamin $E$ and other antioxidants may decrease the incidence of cancer and tumour growth by functioning as anticarcinogens, quenching free radicals or reacting with their products. The association of vitamin $E$ and other serum antioxidants and the risk of cancer in humans was reviewed by Block (1992) and Knekt (1993). Animal studies have given somewhat contradictory results, showing vitamin $E$ to inhibit, or have no effect on, mammary gland, liver, or stomach carcinogenesis, to inhibit or enhance skin cancer, and to inhibit, have no effect on, or enhance colon cancer (Knekt, 1993). The 
Finnish Mobile Clinic Health Survey (Knekt et al. 1991) suggested a significant inverse association between serum vitamin $\mathrm{E}$ and cancer risk. The association was strongest for some gastrointestinal cancers and for the combined group of cancers unrelated to smoking. The prospective study of 89494 women in the Nurses' Health Study (Hunter et al. 1993) showed that large intakes of vitamin $C$ or vitamin $E$ (from food-frequency questionnaires) did not protect women (aged 34-59 years in 1980) against breast cancer. In contrast, the prospective Iowa Women's Health Study (Bostick et al. 1993) of 35215 women showed that most of the association of vitamin $E$ with reduced risk of colon cancer was associated with high intakes of supplemental vitamin $E$ in women under 65 years of age. Those women who developed colon cancer had significantly lower mean daily intakes of dietary, supplemental and total vitamin $E$, and of vitamin $C$. Doubts about the efficacy of supplementation with $\mathrm{TOH}(50 \mathrm{mg} / \mathrm{d})$ on the prevention of lung cancer in male smokers have been raised in a recent report on the Finnish AlphaTocopherol, Beta-Carotene (ATBC) Cancer Prevention Study (Heinonen \& Albanes, 1994).

\section{VITAMIN E AND CARDIOVASCULAR DISEASE}

\section{Platelet aggregation}

The prostacyclin $\left(\mathrm{PGI}_{2}\right)$-thromboxane $\mathrm{A}_{2}\left(\mathrm{TxA}_{2}\right)$ balance plays an important role in determining the thrombotic tendency of the vascular system in mammals. Vitamin $E$ is considered to reduce production of $\mathrm{TxA}_{2}$, a powerful platelet-aggregating factor. Positive effects were reported from a randomized pair-matched, placebo-controlled, double-blind vitamin $\mathrm{E}$ supplementation study in men with low antioxidant status (Salonen et al. 1991). Vitamin E reduced lipid peroxidation and the capacity of platelets to aggregate and to produce $\mathrm{TxA}_{2}$.

\section{Vitamin $E$ and low-density-lipoprotein oxidation}

LDL that have been modified by oxidation have been implicated in the development of atherosclerosis (Steinberg et al. 1989). LDL are not only rich in cholesterol, but also contain high levels of linoleic, arachidonic and docosahexaenoic acid; about 1300 molecules RH are associated with LDL particles of approximately 2.5 MDa (Esterbauer et al. 1992). These RH are highly susceptible to peroxidation by oxidative attack through oxygen radicals. Peroxidation products formed in LDL, probably aldehydes, react with the $\epsilon$-amino groups of lysine residues in apolipoprotein B (Apo B; Steinbrecher et al. 1989). This oxidatively modified LDL no longer binds to the LDL receptor, but to the scavenger receptor of macrophages, and this leads to the conversion of macrophages to lipid-laden foam cells that are found in atherosclerotic plaques.

LDL is protected by TOH (about 6 (range 3-15) mol per mol LDL). Also present are $\gamma$-tocopherol, $\beta$-carotene, lycopene, $\alpha$-carotene, $\beta$-cryptoxanthin, lutein, zeaxanthin, cantaxanthin and phytofluene (Esterbauer et al. 1992). However, these are present in amounts some 20 - to 300 -fold lower than TOH. Thus, the major antioxidant is TOH which resides on the outer layer of the LDL molecule. When isolated LDL was exposed to oxidant stress, the lipid-soluble antioxidants became progressively depleted in the order: TOH, $\gamma$-tocopherol, and then the carotenoids (lycopene first, followed by 
$\beta$-cryptoxanthin, then lutein and zeaxanthin, and finally $\beta$-carotene; Esterbauer et al. 1992). Lipid peroxidation commenced only after depletion of all antioxidants in the LDL (Esterbauer et al. 1992). These authors observed that the oxidative resistance or lag-phase of LDL samples from different non-vitamin E-supplemented donors could not be correlated with TOH, or total antioxidant content. However, supplementation of healthy adults with RRR-TOH led to a significant increase in plasma and LDL-TOH and also a significant correlation between the TOH content of the isolated LDL and resistance to oxidation (Dieber-Rotheneder et al. 1991; Esterbauer et al. 1992). On average, the increases in lag-phase were $18,56,35$ and $75 \%$ for daily oral doses of 150 , 225,800 or $1200 \mathrm{mg}$ for 3 weeks. The efficacy of vitamin $\mathrm{E}$ in protecting LDL varied from person to person. The statistical evaluation of all data in the study $(n 84)$ gave a correlation of $r^{2} 0.51$ between TOH in LDL and the oxidative resistance as measured by the length of the lag-phase preceding oxidation of LDL.

In an extension of this work, Esterbauer et al. (1993) observed a highly significant positive correlation $\left(r^{2} 0.55, P<0.001\right)$ between the duration of the lag-phase $(y ; \mathrm{min})$ and the TOH content $(x ; \mathrm{mol} / \mathrm{mol} \mathrm{LDL})$ of $182 \mathrm{LDL}$ samples which were either unsupplemented or supplemented with $\mathrm{TOH}$ in vitro or in vivo. The relationship was in the form $y=k x+a$, where $k$, the effectiveness of vitamin $\mathrm{E}$, is 3.43 and $a$, vitamin E-independent protection is $49 \cdot 3$. In other words, 1 TOH molecule per LDL particle prolongs the lag-phase by $3.43 \mathrm{~min}$ and the vitamin E-independent residual lag-phase is $49.3 \mathrm{~min}$. This approach allows the prediction of LDL oxidizability for a large group of subjects, but because $k$ and $a$ vary considerably between individuals, it is not possible to predict the oxidizability of LDL of an individual from a knowledge of the TOH content. The mechanism underlying the variations in $k$ and $a$ are not yet understood, but could be related to the mobility of vitamin $\mathrm{E}$ and the content of $\mathrm{RH}$ preformed lipid peroxides, and other antioxidants (e.g. carotenoids) in the LDL particle.

In another recent study, Abbey et al. (1993) supplemented ten men and twelve women with a daily dose of $18 \mathrm{mg} \beta$-carotene, $900 \mathrm{mg}$ vitamin $\mathrm{C}$ and $200 \mathrm{mg}$ TOH for 6 months and measured the LDL antioxidant status. Lag time before the onset of oxidation was significantly lengthened after antioxidant supplementation (28 and 35\% after 3 and 6 months respectively; $P<0.01)$. Plasma TOH was significantly and independently correlated with lag time $(r 0 \cdot 47, P<0 \cdot 01)$. A significant correlation was also seen between lag time and plasma $\beta$-carotene, $(r 0.41, P<0.01)$, but this relationship was not independent of $\mathrm{TOH}$.

Princen et al. (1992) supplemented healthy non-smoking volunteers with $1000 \mathrm{mg}$ DL- $\alpha$-tocopheryl acetate for $7 \mathrm{~d}$ and observed a $3 \cdot 0$ - and $2 \cdot 4$-fold increase in TOH concentration in plasma and LDL respectively. Simultaneously, the oxidation resistance of LDL was elevated significantly $(+41 \%)$ and the rate of oxidation was decreased significantly $(-19 \%)$. The increase in TOH content of LDL and the increase in resistance time were highly correlated $(r 0 \cdot 89, P=0 \cdot 014)$.

Smith et al. (1993) found that approximately $80 \%$ of the antioxidant capacity of LDL, isolated from a number of donors, could be accounted for by the TOH present in the sample.

\section{Vitamin $E$ and ischaemic heart disease (IHD) mortality}

Gey et al. (1991) compared antioxidant concentrations in plasma of middle-aged men (40-59 years) representing sixteen European study populations with the concurrent 
age-specified IHD mortality in the Vitamin Substudy of the WHO/MONICA Project. In twelve of the sixteen populations, which had similar levels of plasma cholesterol and blood pressure but a sixfold difference in mortality, there was no evidence of a relationship between mortality and total cholesterol $\left(r^{2} 0 \cdot 04, P=0 \cdot 53\right)$, blood pressure $\left(r^{2} 0 \cdot 01, P=0 \cdot 80\right)$ or smoking $\left(r^{2} 0.002, P=0 \cdot 89\right)$. However, $63 \%$ of the differences in mortality were accounted for by plasma vitamin $\mathrm{E}\left(r^{2} 0.63, P=0.002\right)$, and $73 \%$ by lipid-standardized plasma vitamin $\mathrm{E}\left(r^{2} 0.73, P=0.0004\right)$. In stepwise- and multipleregression analysis of data from all sixteen populations, $62 \%$ of the differences in IHD mortality were accounted for by lipid-standardized vitamin $\mathrm{E}\left(r^{2} 0 \cdot 62, P=0 \cdot 0003\right)$, with total cholesterol $(17 \%)$, blood pressure $(4 \%)$ and vitamin $A(4 \%)$ increasing this prediction to $87 \%$. Gey et al. (1993a) re-evaluated the MONICA Project data, taking into account the 'Finland factor', which depicts 'a conceivable, yet undefined, but presumably genetic, risk factor' for IHD that might frequently occur in Finland, and observed that the rank order for potential IHD prevention in populations with low antioxidant concentrations is: lipid-standardized vitamin $\mathrm{E}>>$ carotene $=$ vitamin $\mathrm{C}>$ vitamin A. Gey et al. (1993a) proposed that this revised order corresponds fairly well to the rank order of antioxidants in the Edinburgh Angina-Control Study (Riemersma, et al. 1991) and the Basel Prospective Study (Gey et al. 1993b). Linear regression analysis of the data from the Edinburgh Angina-Control Study showed that only vitamin E remained independently and inversely related to risk of angina after adjustment for age, smoking, blood pressure, lipids and relative weight in a population case-control study of 110 patients with angina. The Basel Prospective Study (Gey et al. 1993b) showed that high vitamin $\mathrm{E}$ status was also associated with the lowest rate of $\mathrm{CHD}$ in Europe. Gey et al. (1993a) using data from the three studies calculated that the following antioxidant plasma concentrations $(\mu \mathrm{mol} / \mathrm{l})$ are needed to reduce cardiovascular disease risk: $>27 \cdot 5-30$ lipid-standardized vitamin $E,>0 \cdot 4-0.5 \alpha$ - plus $\beta$-carotene, $>40-50$ vitamin $C$, and $>2 \cdot 2-2 \cdot 8$ lipid-standardized vitamin $\mathrm{A}$.

Two large prospective studies of association between vitamin $\mathrm{E}$ intake (measured by dietary frequency questionnaire and a questionnaire on the use of multivitamin supplements) and risk of CHD showed significantly reduced risk in both women and men who used vitamin E supplements. In The Nurses' Health Study (Stampfer et al. 1993), 87245 female nurses (aged 34-59 years) who were healthy at the beginning of the study were assessed over an 8-year period. The risk of major coronary disease was about $40 \%$ lower in those who took vitamin E supplements for more than 2 years. Supplementation with vitamin $E$ alone (usually at a level of 100 IU or more), or with vitamin $E$ in a multivitamin preparation (usually at a level of 30 IU or less) were both associated with lowered risk, and the reduced risk was significant with vitamin E supplements of $100 \mathrm{IU}$ or more. The Health Professionals Follow-up Study (Rimm et al. 1993), where 39910 males were followed for 4 years, showed that for men consuming at least 100 IU vitamin $\mathrm{E} / \mathrm{d}$ the multivariate relative risk of $\mathrm{CHD}$ was $0 \cdot 63$ (95\% confidence interval $0 \cdot 47-0 \cdot 84$ ). Gey et al. (1993a) concluded that the 'amazingly high inverse correlation of CHD mortality to plasma vitamin $\mathrm{E}$ has been a consistent and most prominent finding' in the MONICA Study. Rimm et al. (1993) and Stampfer et al. (1993) conclude that supplemental vitamin $\mathrm{E}$ may reduce the risk of CHD in both men and women. However, they do not rule out the possibility that confounding factors may partly account for these results. 


\section{Vitamin $E$ and ischaemia-reperfusion injury}

Partially reduced oxygen has been postulated as a primary pathological agent in ischaemia-reperfusion injury. Reperfusion increases the tissue oxygen tension and supports the formation of reduced oxygen species and free radical peroxidation (Janero, 1991). It has been postulated that vitamin $E$ could have a protective and therapeutic role against ischaemia-reperfusion injury in animals. Serbinova et al. (1992) showed that vitamin $\mathrm{E}$ supplementation of rats for 6 weeks protected isolated hearts against ischaemic-reperfusion injury. Preoperative administration of vitamins $A$ and $E$ to ten patients submitted to coronary artery bypass surgery significantly decreased oxidative stress to heart muscle, compared with unsupplemented controls (Ferreira et al. 1991). While laboratory studies suggested that vitamin $\mathrm{E}$ might have protective and therapeutic roles against myocardial ischaemic-reperfusion injury, compelling clinical evidence regarding the therapeutic potential of vitamin $\mathrm{E}$ in IHD patients is lacking (Janero, 1991).

\section{Vitamin $E$ and other disease situations}

Epidemiological evidence suggests an association between cataract incidence and antioxidant status. Robertson et al. (1991) compared the self-reported consumption of supplementary vitamins by 175 cataract patients with that of 175 individually matched, cataract-free patients, and observed that the latter group used significantly more supplementary vitamins E and C. Jackues \& Chylack (1991) also showed that subjects with moderate and low vitamin $E$ intake from foods had an increased risk of cortical cataract relative to subjects with higher intakes. A recent report on a Finnish study (Knekt et al. 1992) showed that low serum levels of vitamin $E$ and $\beta$-carotene were predictors of increased risk of senile cataract in humans.

Human studies indicate that vitamin $\mathrm{E}$ supplementation reduces the oxidative stress and lipid peroxidation induced by exercise. Meydani et al. (1993) demonstrated that $48 \mathrm{~d}$ of vitamin $\mathrm{E}$ supplementation $(727 \mathrm{mg}$ DL- $\alpha$-tocopherol/d) increased muscle $\alpha$-tocopherol and reduced oxidative injury as indicated by sparing of muscle fatty acids, reduced production of muscle lipid conjugated dienes, and reduced excretion of urinary thiobarbituric acid-reactive substances compared with control groups. Vitamin E supplementation $(400 \mathrm{mg} / \mathrm{d})$ prevented an increase in breath pentane exhalation and a decrease in anaerobic threshold at high altitude (Simon-Schnass \& Pabst, 1988). Daily multivitamin supplementation ( $592 \mathrm{mg}$ TOH, $1000 \mathrm{mg}$ ascorbic acid, $30 \mathrm{mg} \beta$-carotene) of healthy males for 6 weeks resulted in significantly lower resting and post-exercise levels of expired pentane and serum malondialdehyde (Kanter et al. 1993).

Free-radical generation associated with ageing may be a contributory factor in the depressed immune response observed in ageing. In a controlled double-blind study in healthy subjects 60 years of age and older, vitamin $E$ supplementation resulted in a significant improvement in several clinical indicators of immune function (Meydani et al. 1990).

\section{CONCLUSIONS}

Oxidative processes are normal cellular events, but uncontrolled oxidation, particularly of membrane lipids and lipoproteins, has been implicated in a variety of degenerative 
conditions, including cardiovascular disease, cancer, cataract, rheumatoid arthritis and ageing. The impressive array of protective mechanisms in the body against oxygen-free radicals, which includes preventative and chain-breaking antioxidants, is an indication of the potentially destructive nature of free-radical-mediated lipid oxidation.

Vitamin $\mathrm{E}$ is the major lipid-soluble chain-breaking antioxidant in biological systems, and because of its location and structure it plays a pivotal role in this antioxidant defence system, harvesting the antioxidant capacity of other lipid- and water-soluble antioxidants, and inhibiting the spread of oxidative damage in membrane lipids and lipoproteins. Evidence is now accumulating that high vitamin $\mathrm{E}$ status decreases the incidence of certain forms of cancer, reduces IHD mortality, and reduces the risk of cataract. In addition, vitamin $E$ protects LDL from oxidation and reduces the damage caused by ischaemia-reperfusion. Further research, including clinical trials, will define more precisely its protective role in these situations and lead to new preventative and therapeutic approaches.

Finally, it should be borne in mind that optimal protection against oxidative damage depends not only on adequate vitamin $E$ status but also on achieving and maintaining the correct balance of fatty acids, carotenoids, vitamins $\mathrm{A}$ and $\mathrm{C}$, trace elements and possibly other dietary components. Furthermore, environmental factors such as smoking, air pollution, exercise, drugs and irradiation also influence the peroxidative process by increasing the level of oxidative stress to which the individual is exposed. Thus, while vitamin $\mathrm{E}$ intakes several times greater than those required to prevent deficiency symptoms have been linked to a lower risk of disease, a concensus on the exact daily intake required for optimal protection against peroxidative damage in individuals is unlikely to be reached for some considerable time.

\section{REFERENCES}

Abbey, M., Nestel, P. J. \& Baghurst, P. A. (1993). Antioxidant vitamins and low-density-lipoprotein oxidation. American Journal of Clinical Nutrition 58, 525-532.

Barclay, L. R. C. \& Ingold, K. U. (1981). Autoxidation of biological molecules. 2. The autoxidation of a model membrane. A comparison of the autoxidation of egg lecithin phosphatidylcholine in water and in chlorobenzene. Journal of the American Chemical Society 103, 6478-6485.

Block, G. (1992). The data support a role for antioxidants in reducing cancer risks. Nutrition Reviews $\mathbf{5 0}$, 207-213.

Bostick, R. M., Potter, J. D., McKenzie, D. R., Sellers, T. A., Kushi, L. H., Steinmetz, K. A. \& Folsom, A. R. (1993). Reduced risk of colon cancer with high intake of vitamin E: The Iowa Women's health study. Cancer Research 53, 4230-4237.

Buettner, G. R. (1993). The pecking order of free radicals and antioxidants: lipid peroxidation, $\alpha$-tocopherol and ascorbates. Archives of Biochemistry and Biophysics 300, 535-543.

Burton, G. W., Joyce, A. \& Ingold, K. U. (1983). Is vitamin E the only chain-breaking antioxidant in human blood plasma and erythroycte membranes? Archives of Biochemistry and Biophysics 221, 281-290.

Burton, G. W. \& Traber, M. G. (1990). Vitamin E: antioxidant activity, biokinetics and availability. Annual Review of Nutrition 10, 357-382.

Cheeseman, K. H. \& Slater, T. F. (editors) (1993). Free radicals in medicine. British Medical Bulletin 49.

Dieber-Rotheneder, M., Puhl, H., Waeg, G., Striegl, G. \& Esterbauer, H. (1991). Effect of oral supplementation with $\mathrm{D}-\alpha$-tocopherol on the vitamin $E$ content of human low density lipoproteins and resistance to oxidation. Journal of Lipid Research 32, 1325-1332.

Diplock, A. T. (editor) (1985). Vitamin E. In Fat-Soluble Vitamins, pp. 154-224. London: Heinemann.

Essenden, R. W., Hitachi, A. \& Nagarajan, V. (1984). Measurement of the dipole moment of a peroxyl radical by microwave dielectric absorption. Journal of Physical Chemistry 88, 107-110. 
Esterbauer, H., Gebicki, J., Puhl, H. \& Jurgens, G. (1992). The role of lipid peroxidation and antioxidants in oxidative modification of LDL. Free Radical Biology and Medicine 13, 341-390.

Esterbauer, H., Puhl, H., Waeg, G., Krebs, A. \& Dieber-Rotheneder, M. (1993). The role of vitamin E in lipoprotein oxidation. In Vitamin E in Health and Disease, pp. 649-671 [L. Packer and J. Fuchs, editors]. New York: Marcel Dekker.

Ferreira, R. F., Milei, J., Llesuy, S., Flecha, B. G., Hourquebie, H., Molteni, L., de Palma, C., Paganini, A., Scervino, L. \& Boveris, A. (1991). Antioxidant action of vitamins A and E in patients submitted to coronary artery bypass surgery. Vascular Surgery 25, 191-195.

Gey, K. F., Moser, U. K., Jordan, P., Stähelin, H. B., Eicholzer, M. \& Lüdin, E. (1993a). Increased risk of cardiovascular disease at suboptimal plasma concentrations of essential antioxidants: an epidemiological update with special attention to carotene and vitamin C. American Journal of Clinical Nutrition 57, 787S-797S.

Gey, K. F., Puska, P., Jordan, P. \& Moser, U. K. (1991). Inverse correlation between plasma vitamin E and mortality from ischemic heart disease in cross-cultural epidemiology. American Journal of Clinical Nutrition 53, 326S-334S.

Gey, K. F., Stähelin, H. B. \& Eicholzer, M. (1993b). Poor plasma status of carotene and vitamin C is associated with higher mortality from ischaemic heart disease and stroke: Basel Prospective Study. Clinical Investigator 71, 3-6.

Halliwell, B. (1987). Oxidants and human diseases: some new concepts. FASEB Journal 1, 358-364.

Halliwell, B. \& Chirico, S. (1993). Lipid peroxidation: its mechanism, measurement and significance. American Journal of Clinical Nutrition 57, 715S-725S.

Halliwell, B. \& Gutteridge, J. M. C. (1990). Role of free radicals and catalytic metal in human diseases: an overview. Methods in Enzymology 186, 1-85.

Heinonen, O. P. \& Albanes, D. (1994). The effect of vitamin $\mathrm{E}$ and beta-carotene on the incidence of lung cancer and other cancers in male smokers. New England Journal of Medicine 330, 1029-1035.

Horwitt, M. K. (1986). Interpretation of requirements for thiamin, riboflavin, niacin-tryptophan and vitamin $E$ plus comments on balance studies and vitamin $\mathrm{B}_{6}$. American Journal of Clinical Nutrition 44, 973-985.

Hunter, D. J., Manson, J. E., Colditz, G. A., Stampfer, M. J., Redner, B., Hennekens, C. H., Speizer, F. E. \& Willett, W. C. (1993). A prospective study of the intake of vitamin C, E and A and the risk of breast cancer. New England Journal of Medicine 329, 234-240.

Jackues, P. F. \& Chylack, L. T. (1991). Epidemiologic evidence of a role for the antioxidant vitamins and carotenoids in cataract prevention. American Journal of Clinical Nutrition 53, 352S-355S.

Janero, D. R. (1991). Therapeutic potential of vitamin E against myocardial ischemic-reperfusion injury. Free Radical Biology and Medicine 10, 315-324.

Kagan, V. E. \& Quinn, P. J. (1988). The interaction of $\alpha$-tocopherol and homologues with other hydrocarbon chains in phospholipid bilayer dispersions. European Journal of Biochemistry 171, 661-667.

Kagan, V. E., Serbinova, E. A., Forte, T., Scita, G. \& Packer, L. (1992). Recycling of vitamin E in human low density lipoproteins. Journal of Lipid Research 33, 385-397.

Kagan, V. E., Serbinova, E. A. \& Packer, L. (1990a). Antioxidant effects of ubiquinones in microsomes and mitochondria are mediated by tocopherol recycling. Biochemical and Biophysical Research Communications 169, 851-857.

Kagan, V. E., Serbinova, E. A. \& Packer, L. (1990b). Recycling and antioxidant activity of tocopherol homologues of differing hydrocarbon chain length in liver microsomes. Archives of Biochemistry and Biophysics 282, 221-225.

Kalyanaraman, B., Morehouse, K. M. \& Mason, R. P. (1991). An electron paramagnetic resonance study of the interaction between the adriamycin semiquinone, hydrogen peroxide, iron chelators and radical scavengers. Archives of Biochemistry and Biophysics 286, 164-170.

Kanter, M. M., Nolte, L. A. \& Holloszy, J. O. (1993). Effects of an antioxidant vitamin mixture on lipid peroxidation at rest and postexercise. Journal of Applied Physiology 74, 965-969.

Kappus, H. (1991). Lipid peroxidation: mechanisms and biological significance. In Free Radicals and Food Additives, pp. 59-75 [O. I. Arouma and B. Halliwell, editors]. London: Taylor \& Francis.

Kaur, H. \& Perkins, M. J. (1991). The free radical chemistry of food additives. In Free Radicals and Food Additives, pp. 17-35 [O. I. Arouma and B. Halliwell, editors]. London: Taylor \& Francis.

Knekt, P. (1993). Epidemiology of vitamin E: Evidence for anticancer effects in humans. In Vitamin $E$ in Health and Disease, pp. 513-527 [L. Packer and J. Fuchs, editors]. New York: Marcel Dekker Inc.

Knekt, P., Aromaa, A., Maatela, J., Aeran, R.-K., Nikkari, T., Hakama, M., Hakulinen, T., Peto, R. \& Teppo, L. (1991). Vitamin E and cancer prevention. American Journal of Clinical Nutrition 53, 283S-286S. 
Knekt, P., Heliovaara, M., Rissanen, A., Aromaa, A. \& Aaran, R. K. (1992). Serum antioxidant vitamins and risk of cataract. British Medical Journal 305, 1392-1394.

Meydani, M., Evans, W. J., Hendelman, G., Biddle, L., Fielding, R. A., Meydani, S. N., Burrill, J., Fiatarone, M. A., Blumberg, J. B. \& Cannon, J. G. (1993). Protective effect of vitamin E on exercise-induced oxidative damage in young and older adults. American Journal of Physiology 264, R992-S998.

Meydani, S. N., Barklund, M. P., Lin, S., Meydani, M., Miller, R. A., Cannon, J. G., Morrow, R. D., Rocklin, R. \& Blumberg, J. B. (1990). Vitamin E supplementation enhances cell mediated immunity in healthy elderly subjects. American Journal of Clinical Nutrition 52, 557-563.

Niki, E. \& Matsuo, M. (1993). Rates and products of reactions of vitamin E with oxygen radicals. In Vitamin $E$ in Health and Disease, pp. 121-130 [L. Packer and J. Fuchs, editors]. New York: Marcel Dekker Inc.

Packer, L. (1993a). Vitamin E: Biological activity and health benefits: Overview. In Vitamin E in Health and Disease, pp. 977-984 [L. Packer \& J. Fuchs, editors]. New York: Marcel Dekker Inc.

Packer, L. (1993b). The vitamin E antioxidant cycle in health and disease. In New Development in Lipid-Protein Interactions and Receptor Function, pp. 297-308 [K. W. A. Wirtz, L. Packer, J. Gustafsson, A. E. Evangelopoulos and J. P. Changeux, editors]. New York: Plenum Press.

Packer, L. \& Kagan, V. E. (1993). Vitamin E. The antioxidant harvesting centre of membranes and lipoproteins. In Vitamin E in Health and Disease, pp. 179-192 [L. Packer and J. Fuchs, editors]. New York: Marcel Dekker Inc.

Princen, H. M. G., van Poppel, G., Vogelezang, C., Buytenkek, R. \& Kok, F. J. (1992). Supplementation with vitamin $\mathrm{E}$ but not $\beta$-carotene in vivo protects low density lipoprotein from lipid peroxidation in vitro. Effect of cigarette smoking. Atherosclerosis and Thrombosis 12, 554-562.

Riemersma, R. A., Wood, D. A. \& Macintyre, C. C. A. (1991). Risk of angina pectoris and plasma concentrations of vitamins $\mathrm{A}, \mathrm{C}$ and $\mathrm{E}$ and carotene. Lancet 337, 1-5.

Rimm, E. B., Stampfer, M. J., Ascherio, A., Giovannucci, E., Colditz, G. A. \& Willett, W. C. (1993). Vitamin E consumption and the risk of coronary heart disease in men. New England Journal of Medicine 328, $1450-1456$.

Robertšon, J. McD., Donner, A. P. \& Trevithick, J. R. (1991). A possible role for vitamins C and E in cataract prevention. American Journal of Clinical Nutrition 53, 3465--3515.

Salonen, J. T., Salonen, R., Seppänen, K., Rinta-Kükka, S., Kükka, M., Kopela, H., Alfthan, G., Kantola, M. \& Schalch, W. (1991). Effect of antioxidant supplementation on platelet function: a randomized pair-matched, placebo-controlled, double-blind trial in men with low antioxidant status. American Journal of Clinical Nutrition 53, 1222-1229.

Serbinova, E. A., Khwaja, S. \& Packer, L. (1992). Palm oil vitamin E protects against ischemia-reperfusion injury in the isolated reperfused Lagendorff heart. Nutrition Research 12, S203-S215.

Simon-Schnass, I. \& Pabst, H. (1988). Influence of vitamin E on physical performance. International Journal of Vitamin and Nutrition Research 58, 49-54.

Smith, D., O'Leary, V. J. \& Darley-Usmar, V. M. (1993). The role of $\alpha$-tocopherol as a peroxyl radical scavenger in human low density lipoprotein. Biochemical Pharmacology 45, 2195-2201.

Stampfer, M. J., Hennekens, C. H., Manson, J. E., Colditz, G. A., Rosner, B. \& Willett, W. C. (1993). Vitamin E consumption and the risk of coronary heart disease in women. New England Journal of Medicine 328, 1444-1449.

Steinberg, D., Parthasarathy, S., Carew, T. E., Khoo, J. C. \& Witztum, J. L. (1989). Beyond cholesterol. Modification of low-density lipoprotein that increases its atherogenicity. New England Journal of Medicine 320, 915-924.

Steinbrecher, U. P., Longheed, M., Kwan, W. C. \& Dirks, M. (1989). Recognition of oxidized low density lipoprotein by the scavenger receptor of macrophages results from derivatization of apolipoprotein B by products of fatty acid peroxidation. Journal of Biological Chemistry 264, 15216-15223. 